\title{
Efficacy and safety of sustained-delivery fluocinolone acetonide intravitreal implant in patients with chronic diabetic macular edema insufficiently responsive to available therapies: a real-life study
}

\author{
This article was published in the following Dove Press journal: \\ Clinical Ophthalmology \\ 8 July 2016 \\ Number of times this article has been viewed
}

Pascale Massin

Ali Erginay

Bénédicte Dupas

Aude Couturier

Ramin Tadayoni

Ophthalmology Department, Lariboisière Hospital, Paris, France
Correspondence: Pascale Massin Service d'Ophtalmologie, Hôpital Lariboisière, 2 rue Ambroise Paré, 75010 Paris, France

Tel +33 (I) 49952474

Email pascale.massin I@gmail.com
Purpose: To evaluate the efficacy and safety of sustained-delivery fluocinolone acetonide (FAc) intravitreal implant for diabetic macular edema (DME).

Patients and methods: Prospective study in patients with DME insufficiently responsive to laser and anti-vascular endothelial growth factor (anti-VEGF). Patients with history of rise of intraocular pressure after intravitreal corticosteroids were excluded.

Results: The macular edema rapidly decreased both in group 1 (prior laser only; $n=7$ eyes) and group 2 (prior laser and $\geq 3$ monthly anti-VEGF therapy; $\mathrm{n}=10$ eyes) and central subfield thickness was reduced by $-299 \mu \mathrm{m}(P=0.008)$ and $-251 \mu \mathrm{m}(P=0.016)$ at 12 months, respectively. Mean area under the curve from baseline to last value for pseudophakic eyes was +4.2 letters in group 1 and +9.5 letters in group 2. Overall, the FAc implant was well tolerated.

Conclusion: This prospective study confirms the efficacy of the FAc implant in DME patients insufficiently responsive to laser and anti-VEGF. Moreover, with a careful patient selection, our safety results would support an earlier use of FAc in the DME treatment pathway.

Keywords: diabetic macular edema, intravitreal corticosteroid, corticosteroid intravitreal implant, fluocinolone acetonide

\section{Introduction}

Diabetic macular edema (DME) is the primary cause of vision loss in diabetic retinopathy, which is the leading cause of blindness in individuals aged 20-70 years in developed countries. ${ }^{1,2}$ The global prevalence of diabetic retinopathy among diabetics is $\sim 35 \%$ and DME is reported in $6.8 \%$ of diabetics. ${ }^{3}$ A bilateral disease was reported in 33\%-41.5\% of patients with DME. ${ }^{4,5}$ According to the Early Treatment Diabetic Retinopathy Study, between $25 \%$ to $33 \%$ of eyes with clinically significant macular edema experience a visual loss of 15 letters or more within 3 years if left untreated. ${ }^{6}$

The pathophysiology of DME is a complex process initiated by hyperglycemia and leading to dilated capillaries and retinal microaneurysms. ${ }^{7}$ Angiogenesis, inflammation, and oxidative stress contribute to the pathogenesis of DME.$^{8-10}$ The consequences are an impairment of the blood-retinal barrier, an increase of vascular permeability, and finally an accumulation of fluid in retinal tissue..$^{8,10,11}$ At early stages, vascular endothelial growth factor (VEGF) is the major driver of retinal changes, whereas in chronic DME, sustained inflammatory processes are primarily responsible. ${ }^{12}$ Indeed, 
the breakdown of the vascular barrier and inflammatory processes induces an influx of macrophages and leukocytes, which are thought to play a role in the chronic inflammation of diabetic retinopathy. ${ }^{13}$ A recent study demonstrated that the aqueous humor levels of some cytokines and chemokines associated with angiogenesis and inflammation (VEGF, interleukin [IL]-1 $\beta$, IL-6, IL-8, monocyte chemoattractant protein-1, etc) were higher in patients with diabetic retinopathy and that the levels of all these cytokines, except VEGF, were closely correlated with the severity of diabetic retinopathy. ${ }^{14}$ This suggests that anti-inflammatory agents with sustained action should be useful to control the inflammatory component of diabetic retinopathy and consequently to improve DME. ${ }^{15}$

Laser photocoagulation is the first treatment to have demonstrated its efficacy in the treatment of the visual loss related to DME. ${ }^{15}$ Intravitreal injections of corticosteroids are also used, but they provide a short-term release of the active compound and repeated injections are needed. ${ }^{15}$ More recently, intravitreal injections of anti-VEGF were approved for the same indication. The relative efficacy and safety of intravitreous aflibercept, bevacizumab, and ranibizumab in the treatment of DME was studied in the Diabetic Retinopathy Clinical Research Network protocol T. A gain of around 10 letters was obtained in the global population against monthly injections potentially difficult to manage in real life. ${ }^{16}$ A recent meta-analysis suggested an increased risk for death and potentially for cerebrovascular accidents in patients with DME, who received 2 years of monthly treatment with anti-VEGF agents. ${ }^{17}$

Innovative biotechnological techniques and new polymers led to the development of new intravitreal drug delivery systems. ${ }^{18,19}$ Thus, the sustained-delivery fluocinolone acetonide (FAc) intravitreal implant (ILUVIEN ${ }^{\circledR}$, Alimera Sciences, Inc., Alpharetta, GA, USA), has been approved for DME. The Fluocinolone Acetonide in Human Aqueous Study demonstrated the sustained-delivery of FAc over the course of a 36-month period with this drug. ${ }^{20}$ Phase III trials demonstrated the efficacy of ILUVIEN with marked improvements in best-corrected visual acuity (BCVA) in patients with DME..$^{21,22}$ Intravitreal delivery of corticosteroids requires regular monitoring for increased intraocular pressure (IOP) and cataract formation.

Although the FAc implant represents a new option in patients with chronic DME, there are limited data available on the real-life long-term use of ILUVIEN. Moreover, at the time the Phase III trials of ILUVIEN were conducted, antiVEGF therapies were not approved and therefore were not yet a typical standard of care for treating DME. The present study assessed changes in central subfield thickness (CST) and BCVA following treatment with intravitreal FAc implant in chronic DME patients with insufficient response to previous treatments.

\section{Materials and methods Study design}

This was an open-label, single-center, Phase IV study of the efficacy and safety of FAc intravitreal implant (ILUVIEN) in chronic DME patients considered insufficiently responsive to laser and anti-VEGF treatment.

Patients aged $\geq 18$ years were eligible to participate if they met the following criteria: DME based on investigator's clinical evaluation and demonstrated using fundoscopic photography and spectral domain optical coherence tomography; mean CST $\geq 350 \mu \mathrm{m}$ in the study eye; vision impairment (20/60-20/400 using Snellen visual acuity equivalent) related to DME; patients considered as insufficiently responsive to prior therapy for DME as defined by the study physician. Two groups were defined in advance: group 1 included patients having received previous treatment in the study eye with laser photocoagulation for DME at least 3 months prior to the screening visit and no previous treatment with intraocular anti-VEGF therapy (anti-VEGF considered inappropriate); group 2 included patients previously treated in the study eye with laser photocoagulation for DME, including focal/grid and pan-retinal, at least 3 months prior to the screening visit and with past history of $\geq 3$ monthly anti-VEGF treatments.

Patients were excluded if they met one of the following criteria in the study eye: IOP $>21 \mathrm{mmHg}$ at screening; history of rise in IOP $>25 \mathrm{mmHg}$ following treatment with an intravitreal corticosteroid; use of $\geq 2$ active agents as IOPlowering medications to control IOP at screening; tractional DME and media opacities; severe proliferative diabetic retinopathy requiring pan retinal photocoagulation; pregnant or breastfeeding women; diagnosis of active angiographic central vein ischemia prior to screening; pan-retinal photocoagulation or cataract surgery within 3 months before inclusion; contraindications according to the current Summary of Product Characteristics, ${ }^{23}$ pre-existing glaucoma; active or suspected ocular or periocular infection; and hypersensitivity to the active agent or to one of the excipients.

Written informed consent was obtained from each patient. The protocol was conducted in accordance with the Declaration of Helsinki and French law for biomedical research. The protocol was approved by the institutional ethics committee of Ile-de-France IV (Saint Louis, Paris, France). 
The study was registered with the Clinical Trials identifier NCT02472366. The trial was conducted from January 2014 to April 2015.

\section{Study treatment}

The implant is an injectable intraocular sustained-release drug delivery system for FAc preloaded into a one-time use sterile applicator. Each implant contains $0.19 \mathrm{mg}$ of FAc as the active ingredient within a cylindrical polyimide tube measuring $3.5 \mathrm{~mm}$ long and $0.37 \mathrm{~mm}$ diameter. The implant is injected through the pars plana into the vitreous using the $25 \mathrm{G}$ applicator.

All patients received ILUVIEN $190 \mu \mathrm{g}$ intravitreal implant with an initial release rate of $0.2 \mu \mathrm{g} /$ day at inclusion visit. The implant was administered by injection according to the method of administration defined in the Summary of Product Characteristics. ${ }^{23}$ Only one eye of each patient was treated with ILUVIEN, except for one patient in group 1. The other (nonstudy) eye received ocular treatments at the discretion of the investigator.

\section{Visits and assessments}

Patient assessments were performed at screening, baseline, week 1, months 1, 3, 6, 9, and 12. Demographic, medical/ ophthalmic history, and diabetes history were recorded at screening visit. Ophthalmic examination, including BCVA, IOP, spectral time-domain optical coherence tomography, slit lamp examination, and dilated ophthalmoscopy were performed at screening visit and at all follow-up visits. Fundus photography and diabetic retinopathy assessment were performed at screening visit, month 6, and month 12 . Concomitant medications, ocular procedures, and adverse events were recorded during the follow-up visits.

\section{Statistical analysis}

The total sample size was expected to be 20 patients. This sample size was considered to allow an adequate estimation of safety events.

The study was descriptive in nature and only exploratory analysis was conducted. All patients enrolled in intentionto-treat population who had a valid baseline assessment were analyzed. Mean CST and BCVA were compared at each visit with baseline values using Student's paired $t$-test. Mean change of the area under the curve from baseline to last value was calculated for BCVA using the trapezoidal rule divided by the total duration in days and a Student's paired $t$-test was used for comparison with baseline values for each group.

Safety variables were analyzed using the safety population that included data from all enrolled patients who received the FAc intravitreal implant.

The analyses were performed using SAS version 9.0 (SAS Institute, Inc., Cary, NC, USA). A $P$-value $<0.05$ was considered to be significant.

\section{Results}

\section{Baseline characteristics of study patients}

The demographics of patients $(n=16)$ and baseline characteristics of study eyes $(n=17)$ are described in Table 1. One patient in group 1 received the study drug in both eyes. Eyes with prior

Table I Demographics and baseline characteristics of study patients and eyes

\begin{tabular}{|c|c|c|}
\hline Characteristics & Group I, prior laser only & Group 2, prior laser and anti-VEGF \\
\hline Patients, $\mathrm{n}$ & 6 & 10 \\
\hline Age, years, median (range) & $67(55-8 I)$ & $64(39-75)$ \\
\hline Male sex, n (\%) & $4(66)$ & $5(50)$ \\
\hline Type 2 diabetes, $\mathrm{n}(\%)$ & $5(83)$ & $7(70)$ \\
\hline $\mathrm{HbAlc}$ \%, mean (SD) & $8.2(1.2)$ & $8.1(1.6)$ \\
\hline Eyes, $n$ & 7 & 10 \\
\hline Right study eye, n (\%) & $4(57)$ & $6(60)$ \\
\hline Pseudophakic lens status, n (\%) & $7(100)$ & $5(50)$ \\
\hline Duration of DME, years, median (range) & $7.6(3.2-11.6)$ & $3.6(0.9-9.7)$ \\
\hline Prior intravitreal corticosteroid, $\mathrm{n}(\%)$ & $6(86)$ & $8(80)$ \\
\hline$B C V A$, mean $(S D)$, letters & $47.7(10.1)$ & $44.8(12.2)$ \\
\hline BCVA Snellen, median (range) & $20 / 100(20 / 200-20 / 63)$ & $20 / 125(20 / 320-20 / 63)$ \\
\hline CST, mean (SD), $\mu \mathrm{m}$ & $573(103)$ & $701(205)$ \\
\hline Corneal thickness, mean (SD), $\mu \mathrm{m}$ & $550.6(39.7)$ & $548.4(52.6)$ \\
\hline \multicolumn{3}{|l|}{ Diabetic retinopathy severity, n (\%) } \\
\hline Severe nonproliferative diabetic retinopathy & 0 & $I(10)$ \\
\hline Laser (pan-retinal photocoagulation) & $7(100)$ & $9(90)$ \\
\hline
\end{tabular}

Abbreviations: BCVA, best-corrected visual acuity; CST, center subfield thickness; DME, diabetic macular edema; HbAIc, hemoglobin AIc; VEGF, vascular endothelial growth factor; SD, standard deviation. 
laser therapy only (group 1) had a longer median duration of DME than eyes with prior laser plus anti-VEGF (group 2): 7.6 versus 3.6 years. Six patients $(86 \%)$ in group 1 and 8 patients (80\%) in group 2 had been treated with intravitreal steroid injections previously. Twelve eyes were pseudophakic ( 7 in group 1 and 5 in group 2). All patients had been treated with macular laser and had diabetic retinopathy controlled by panretinal photocoagulation (except one patient in group 2).

At inclusion, the mean CST was $573 \mu \mathrm{m}$ in group 1 and $701 \mu \mathrm{m}$ in group 2. Mean BCVA at inclusion was comparable in both groups (Table 1).

\section{Efficacy of FAc implants on macular edema and visual acuity}

The macular edema significantly decreased in both groups as early as 1 week after intravitreal administration of the implant (Table 2). The mean change of CST was higher in group 1 compared with group 2 . Thus, after 1 month, the mean change of CST was $-239 \mu \mathrm{m}$ in group 1 and $-147 \mu \mathrm{m}$ in group 2; at month 12, these changes were -299 and $-251 \mu \mathrm{m}$, respectively. At month 12, patients of group 1 and group 2 achieved a mean value of CST at $274 \mu \mathrm{m}(P=0.008)$ and $450 \mu \mathrm{m}$ $(P=0.016)$, respectively (Figure 1).
The mean letter gain in BCVA score was +4.7 in group 1 and +4.4 in group 21 week after intravitreal injection of the study drug and improvement was maintained up to 12 months (Table 2). Eyes with an improvement of $\geq 5$ letters at least once during the study were 4/7 in group 1 and 5/10 in group 2. Mean area under the curve from baseline to last value for pseudophakic eyes was +4.21 in group 1 and +9.54 in group 2 (Table 2).

Four patients also received top-up therapies. Three patients in group 2 received intravitreal injections of antiVEGF followed for one patient by one dexamethasone implant (at days 69, 54, 332, and 342, respectively). One patient in group 1 received one triamcinolone injection (at day 116). This patient had a sustained visual gain until 8 months after receiving the rescue therapy and did not need any other adjuvant therapy. However, these patients did not show any significant BCVA gain after the additional therapies despite a gain in CST. The mean BCVA gain was increased in group 2 from +0.9 to +4.4 after excluding values post-rescue (Figure 2).

All patients were pseudophakic except five patients included in group 2. The mean gain of BCVA in group 2 further increased to +9.4 letters in the five pseudophakic patients

Table 2 Efficacy results for CST and BCVA at defined times after insertion of the fluocinolone acetate implant (intention-to-treat population)

\begin{tabular}{|c|c|c|c|c|}
\hline \multirow[t]{2}{*}{ Study visits } & \multicolumn{2}{|c|}{ Group I, prior laser only ( $n=7$ eyes) } & \multicolumn{2}{|c|}{ Group 2, prior laser and anti-VEGF ( $n=10$ eyes) } \\
\hline & Mean change (SD) & $P$-value ${ }^{a}$ & Mean change (SD) & $P$-value ${ }^{a}$ \\
\hline \multicolumn{5}{|l|}{ Week I } \\
\hline $\mathrm{CST}, \mu \mathrm{m}$ & $-156(58)$ & $<0.001$ & $-110(114)$ & 0.013 \\
\hline BCVA score, letters & $+4.7(4.7)$ & 0.037 & $+4.4($ (II.4) & 0.255 \\
\hline \multicolumn{5}{|l|}{ Month I } \\
\hline $\mathrm{CST}, \mu \mathrm{m}$ & $-239(77)$ & $<0.001$ & $-147(196)$ & 0.042 \\
\hline BCVA score, letters & $+2.0(5.9)$ & 0.408 & $+6.4(11.8)$ & 0.120 \\
\hline \multicolumn{5}{|l|}{ Month 3} \\
\hline $\mathrm{CST}, \mu \mathrm{m}$ & $-227(145)$ & 0.006 & $-167(208)$ & 0.032 \\
\hline BCVA score, letters & $+3.7(6.1)$ & 0.158 & $+7.8(12.4)$ & 0.077 \\
\hline \multicolumn{5}{|l|}{ Month 6} \\
\hline $\mathrm{CST}, \mu \mathrm{m}$ & $-28 I(202)$ & 0.010 & $-167(249)$ & 0.062 \\
\hline BCVA score, letters & $+4.3(5.5)$ & 0.085 & $+4.8(13.5)$ & 0.291 \\
\hline \multicolumn{5}{|l|}{ Month 9} \\
\hline $\mathrm{CST}, \mu \mathrm{m}$ & $-295(206)$ & 0.009 & $-172(235)$ & 0.046 \\
\hline BCVA score, letters & $+5.3(7.0)$ & 0.091 & $0.4(5.1)$ & 0.939 \\
\hline \multicolumn{5}{|l|}{ Month 12} \\
\hline $\mathrm{CST}, \mu \mathrm{m}$ & $-299(206)$ & 0.008 & -25 I (269) & 0.016 \\
\hline BCVA score, letters & $+5.6(8.7)$ & 0.141 & $+0.9(15.8)$ & $0.86 \mathrm{I}$ \\
\hline \multicolumn{5}{|l|}{$A \cup C_{0 \text {-last, letters }}$} \\
\hline All eyes & $+4.21(5.77)$ & 0.102 & $+3.97(12.07)$ & 0.326 \\
\hline Pseudophakic eyes ${ }^{\mathrm{b}}$ & $+4.21(5.77)$ & 0.102 & $+9.54(6.65)$ & 0.225 \\
\hline
\end{tabular}

Notes: ${ }^{\text {CCompared }}$ with baseline value (Student's $t$-test) for paired values. ${ }^{b} \mathrm{n}=7$ for group $\mathrm{I}$ and $\mathrm{n}=5$ for group 2 .

Abbreviations: $\mathrm{AUC}_{0 \text {-last }}$, area under the curve from baseline to last value; BCVA, best-corrected visual acuity; CST, central subfield thickness; VEGF, vascular endothelial growth factor. 


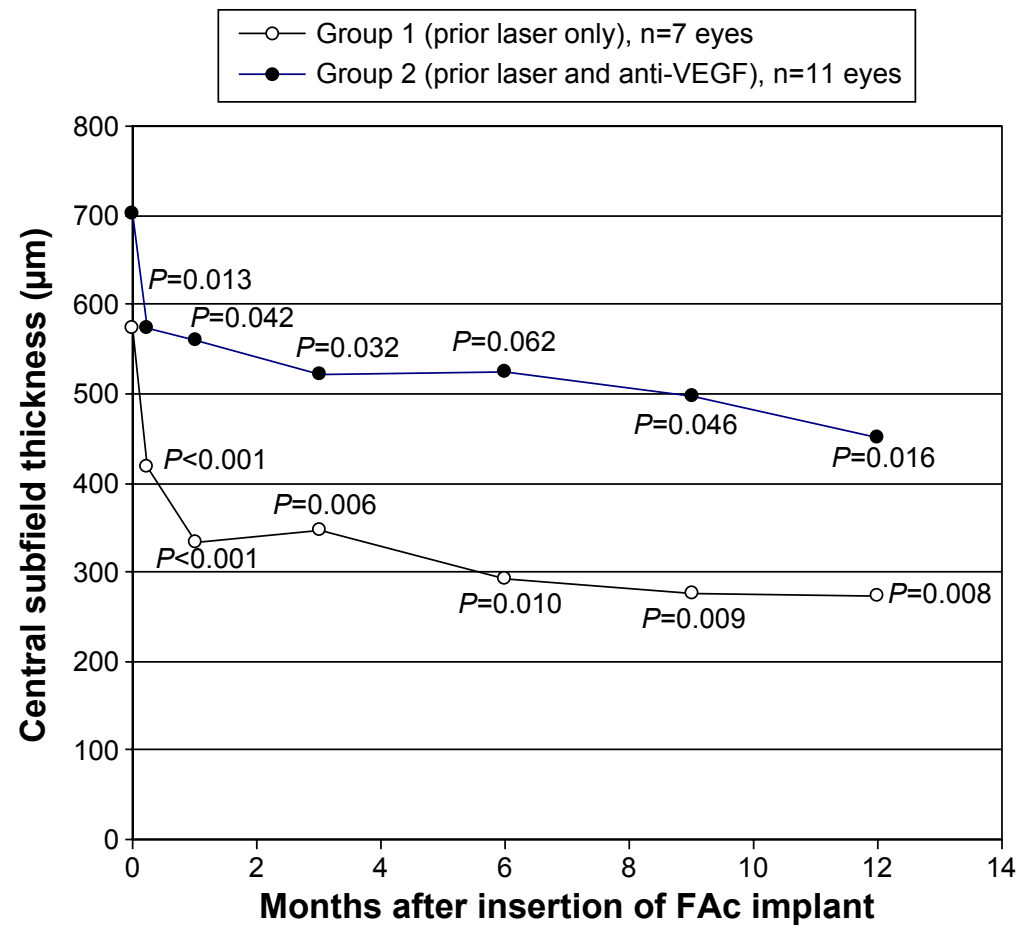

Figure I Evolution of central subfield thickness after intravitreal insertion of FAc implant. $P$-values are for comparison with baseline value. Abbreviations: FAc, fluocinolone acetonide; VEGF, vascular endothelial growth factor.

(Figure 3). Two phakic patients had a loss of -23 and -24 letters of BCVA. Only one extraction of the cataract was performed during the study at month 7 followed by a gain of 13 letters at month 12 compared with baseline for this patient.

\section{Safety}

There was no death and no treatment discontinuation due to the study drug. No serious adverse event related to study drug was reported. Four serious adverse events unrelated to the study drug were reported in two patients (stroke, cataract surgery in study eye, cataract surgery in the fellow eye, and vitrectomy in the other eye).

Reported adverse events suspected to be related to study drug were all high IOP: one patient in group 1 (maximal IOP value: $32 \mathrm{mmHg}$ at month 1 ) and two patients in group 2 (25 mmHg at month 3 and $28 \mathrm{mmHg}$ at month 12). These three patients had their IOP well controlled by IOP-lowering eyedrops (group 1: triple-drug combination; group 2:

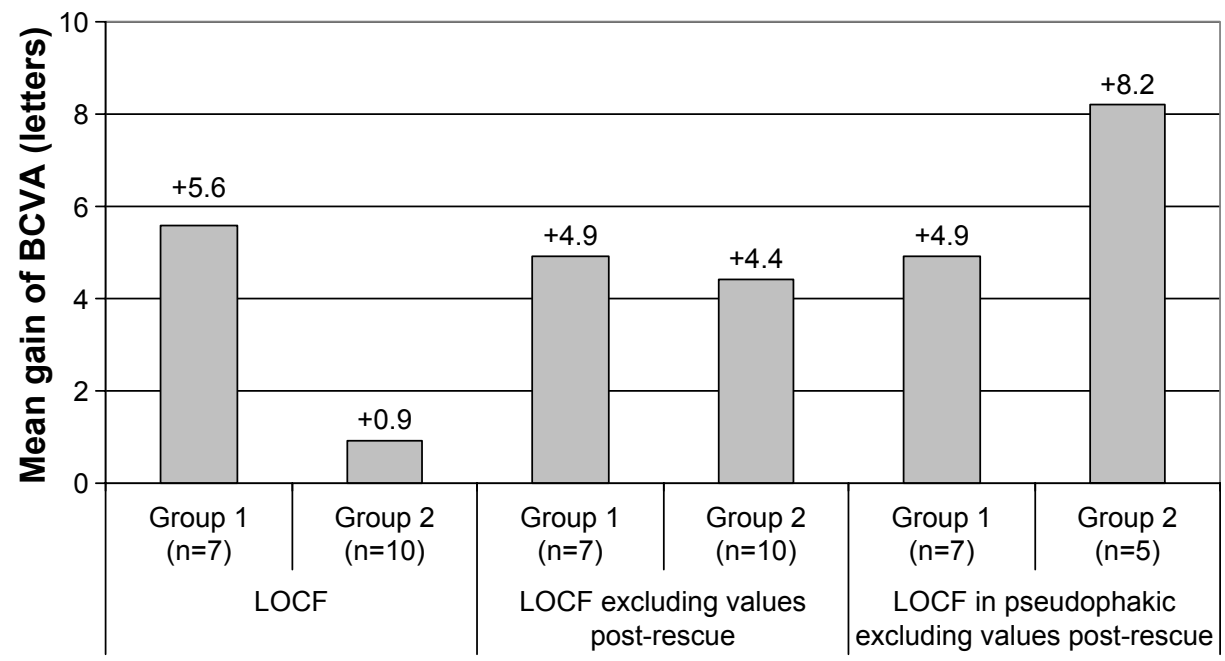

Figure 2 Mean gain of visual acuity after I year of treatment after intravitreal insertion of FAc implant (intention-to-treat population with LOCF). Abbreviations: FAc, fluocinolone acetonide; BCVA, best-corrected visual acuity; LOCF, last observation carried forward. 


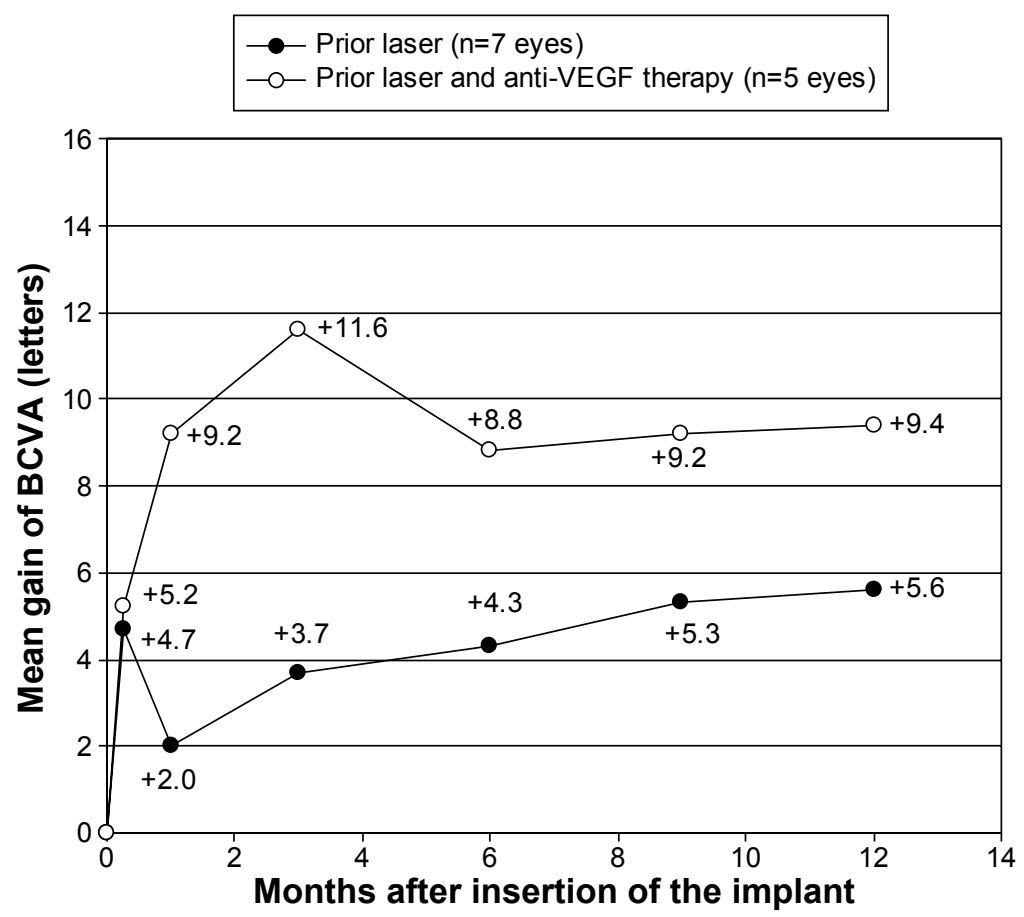

Figure 3 Mean gain of visual acuity during study in pseudophakic patients (intention-to-treat population). Abbreviations: BCVA, best-corrected visual acuity; VEGF, vascular endothelial growth factor.

two successive single drug treatments for one patient and two-drug combination for the other one). Mean IOP remained stable in both groups from baseline to month 12: from $15.3 \pm 2.7$ to $16.8 \pm 3.5 \mathrm{mmHg}$ in group 1 and from $15.5 \pm 2.5$ to $18.2 \pm 4.7 \mathrm{mmHg}$ in group 2 .

\section{Discussion}

The main objective of this study was to assess the efficacy and safety of FAc intravitreal implants in patients with chronic DME insufficiently responsive to prior macular laser and anti-VEGF therapy.

Two populations were analyzed in our trial: group 1 with chronic DME treated by laser and group 2 with antiVEGF treatment added to the therapeutic armamentarium. At inclusion, the first population mainly comprised patients with a response to steroids that was not maintained; the second population comprised patients with recurrent edema despite at least three injections of anti-VEGF injected as loading dose.

At baseline, the mean CST was $573 \mu \mathrm{m}$ in group 1 and $701 \mu \mathrm{m}$ in group 2, indicating relatively severe edema. In Fluocinolone Acetonide for Macular Edema (FAME) studies (Phase III trials for efficacy and safety of FAc implant in DME patients), the mean CSTs of the three randomized groups at baseline were 451,461 , and $485 \mu \mathrm{m} .{ }^{21,22}$ In our study, at month 1 , the mean decrease of CST was $-239 \mu \mathrm{m}$ in group 1 and was $-147 \mu \mathrm{m}$ in group 2 . This decrease was rapid and a significant benefit on macular edema was obtained as early as 1 week after the injection of the study drug. Eyes of group 1 had a mean CST of $573 \mu \mathrm{m}$ at baseline and achieved a mean value of $274 \mu \mathrm{m}$ at month 12 to be compared with $<250 \mu \mathrm{m}$, which is the mean thickness of the retina considered as normal or near-normal; eyes of group 2 achieved a mean CST of $450 \mu \mathrm{m}$ at month 12. In the study by Bressler et $\mathrm{al}^{24}$ that assessed the factors associated with changes in BCVA and CST in DME eyes treated with ranibizumab, eyes with a greater CST at baseline were more likely to achieve greater reduction, but less likely to reach $<250 \mu \mathrm{m}$.

In contrast with the anatomical improvements, the benefit in BCVA letter score was more limited and heterogeneous, some patients achieving high improvements of visual acuity, whereas others were not improved. The mean improvement of BCVA letter score (excluding values post-rescue) was +4.9 in group 1 and +4.4 in group 2 after 1 year. This last parameter in group 2 achieved +8.2 in pseudophakic patients only $(\mathrm{n}=5)$.

As a consequence, there was no clear correlation at the individual level between improvement of visual acuity and decrease of macular edema. This was particularly obvious in group 1, which included only pseudophakic eyes: the large decrease of the CST was not translated in terms of visual acuity. A low correlation between CST and visual acuity 
is frequent in diabetes. ${ }^{25}$ This discordance is also observed after intravitreal injections of treatments in diabetic patients. Indeed, a long duration of macular edema and its consequences, such as atrophy of the external layers of the retina, makes it difficult to achieve a functional improvement. ${ }^{26-28}$ In a recent paper, a correlation between ganglion cell layer thinning and poor visual function after resolution of DME was reported..$^{29}$ Microperimetry may be more sensitive than BCVA to evaluate functional response after intravitreal therapy in DME. ${ }^{30,31}$ The study by Dubois-Roussel et al ${ }^{32}$ found that more than half of patients with DME treated with the FAc implant with a favorable anatomic response, but poor visual acuity gain, showed nevertheless an improvement in stability of the fixation point. These results suggest that patients treated with FAc implants could achieve better visual performances than expected according to scores of BCVA alone.

Our study has some limitations that are related in part to its observational design and the small number of patients. The patients were not randomized and there was no comparison with reference treatment or sham group. Moreover, the study allowed the physicians to modify the treatment if they considered that the disease progressed. Thus, four eyes also received other therapies. The analysis without post-additional therapies values allowed assessing the specific effect of the FAc intravitreal implant. These characteristics, together with the low numbers of patients, are certainly limitations to this study. Nevertheless, the present study is the first to report prospective data on efficacy and safety of FAc intravitreal implants in patients with prior anti-VEGF treatment and in patients who could not receive anti-VEGF treatment. Indeed, patients initially treated with anti-VEGF have not been assessed in the FAME studies. Results comparable to ours were recently reported by Schmit-Eilenberger ${ }^{33}$ from retrospective registry data in 10 DME patient population (15 eyes) that were refractory to other therapies and treated with the $190 \mu \mathrm{g}$ FAc implant.

The FAc implant was well tolerated in all patients of our study. Only 1 eye out of 17 achieved IOP $\geq 30 \mathrm{mmHg}$. High IOP was reported as adverse event suspected to be related to study drug in three patients; all three events were well controlled by medical treatment. In the FAME study, 38.4\% of patients receiving the FAc implant $(0.2 \mu \mathrm{g} /$ day $)$ received IOP-lowering medication and $18.4 \%$ experienced an increase in IOP $>30 \mathrm{mmHg} .{ }^{21}$ In our study, the patients with a previous history of intravitreal corticosteroid treatment followed by a rise in IOP $>25 \mathrm{mmHg}$ were excluded (14/17 patients had received prior intravitreal corticosteroid). Thus, a careful selection of patients appears to improve safety of sustaineddelivery FAc intravitreal implants.

Better results in terms of CST were obtained in group 1 compared with group 2, which had worse BCVA, worse CST, and more anti-VEGF injections. Therefore, these results are in favor of an earlier use of the FAc implant in selected patients. Indeed, reduction of CST during the first year of treatment is associated with better visual outcomes. ${ }^{24}$ Earlier use of the FAc intravitreal implant is also supported by the recent analyses of Downey and Chakravarthy, ${ }^{34}$ with results supporting corticosteroid therapy in patients with chronic diabetic macular edema regardless of baseline visual acuity.

\section{Conclusion}

In this population of difficult-to-treat patients with severe DME, a rapid and sustained improvement of macular edema was obtained after treatment with FAc intravitreal implant. Pseudophakic patients had a clinically significant gain of visual activity 1 year after injection. Therefore, this study confirms the efficacy of the FAc implant in DME patients insufficiently responsive to laser and anti-VEGF. Moreover, the safety data support its earlier use in patients after insufficient response to anti-VEGF and already known to be tolerant to corticosteroids.

\section{Disclosure}

Pascale Massin, Ali Erginay, Bénédicte Dupas, and Ramin Tadayoni are consultants for Alimera, and report no other conflicts of interest in this work. Aude Couturier reports no conflicts of interest in this work.

\section{References}

1. Klein R, Lee KE, Gangnon RE, Klein BE. The 25-year incidence of visual impairment in type 1 diabetes mellitus the wisconsin epidemiologic study of diabetic retinopathy. Ophthalmology. 2010;117(1):63-70.

2. Moss SE, Klein R, Klein BE. The 14-year incidence of visual loss in a diabetic population. Ophthalmology. 1998;105(6):998-1003.

3. Yau JW, Rogers SL, Kawasaki R, et al. Global prevalence and major risk factors of diabetic retinopathy. Diabetes Care. 2012;35(3):556-564.

4. Minassian DC, Owens DR, Reidy A. Prevalence of diabetic macular oedema and related health and social care resource use in England. Br J Ophthalmol. 2012;96(3):345-349.

5. Klein R, Klein BE, Moss SE, Cruickshanks KJ. The Wisconsin Epidemiologic Study of Diabetic Retinopathy. XV. The long-term incidence of macular edema. Ophthalmology. 1995;102(1):7-16.

6. Bhagat N, Grigorian RA, Tutela A, Zarbin MA. Diabetic macular edema: pathogenesis and treatment. Surv Ophthalmol. 2009;54(1):1-32.

7. Antonetti DA, Lieth E, Barber AJ, Gardner TW. Molecular mechanisms of vascular permeability in diabetic retinopathy. Semin Ophthalmol. 1999; 14(4):240-248.

8. Ehrlich R, Harris A, Ciulla TA, Kheradiya N, Winston DM, Wirostko B. Diabetic macular oedema: physical, physiological and molecular factors contribute to this pathological process. Acta Ophthalmol. 2010;88(3) 279-291. 
9. Funatsu H, Noma H, Mimura T, Eguchi S, Hori S. Association of vitreous inflammatory factors with diabetic macular edema. Ophthalmology. 2009; 116(1):73-79.

10. Joussen AM, Poulaki V, Le ML, et al. A central role for inflammation in the pathogenesis of diabetic retinopathy. FASEB J. 2004;18(12): $1450-1452$.

11. Klaassen I, Van Noorden CJ, Schlingemann RO. Molecular basis of the inner blood-retinal barrier and its breakdown in diabetic macular edema and other pathological conditions. Prog Retin Eye Res. 2013;34: $19-48$.

12. Tang J, Kern TS. Inflammation in diabetic retinopathy. Prog Retin Eye Res. 2011;30(5):343-358.

13. Funatsu H, Yamashita H, Noma H, et al. Aqueous humor levels of cytokines are related to vitreous levels and progression of diabetic retinopathy in diabetic patients. Graefes Arch Clin Exp Ophthalmol. 2005; 243(1):3-8.

14. Dong N, Xu B, Wang B, Chu L. Study of 27 aqueous humor cytokines in patients with type 2 diabetes with or without retinopathy. Mol Vis. 2013; 19:1734-1746.

15. Das A, McGuire PG, Rangasamy S. Diabetic macular edema: pathophysiology and novel therapeutic targets. Ophthalmology. 2015;122(7): 1375-1394.

16. Wells JA, Glassman AR, Ayala AR, et al; Diabetic Retinopathy Clinical Research Network. Aflibercept, bevacizumab, or ranibizumab for diabetic macular edema. N Engl J Med. 2015;372(13):1193-1203.

17. Avery RL, Gordon GM. Systemic safety of prolonged monthly anti-vascular endothelial growth factor therapy for diabetic macular edema: a systematic review and meta-analysis. JAMA Ophthalmology. 2015:21-29.

18. Callanan DG, Gupta S, Boyer DS, et al; Ozurdex PLACID Study Group. Dexamethasone intravitreal implant in combination with laser photocoagulation for the treatment of diffuse diabetic macular edema. Ophthalmology. 2013;120(9):1843-1851.

19. Kane FE, Burdan J, Cutino A, Green KE. Iluvien: a new sustained delivery technology for posterior eye disease. Expert Opin Drug Deliv. 2008;5(9):1039-1046.

20. Campochiaro PA, Nguyen QD, Hafiz G, et al; FAMOUS Study Group. Aqueous levels of fluocinolone acetonide after administration of fluocinolone acetonide inserts or fluocinolone acetonide implants. Ophthalmology. 2013;120(3):583-587.

21. Campochiaro PA, Brown DM, Pearson A, et al; FAME Study Group. Sustained delivery fluocinolone acetonide vitreous inserts provide benefit for at least 3 years in patients with diabetic macular edema. Ophthalmology. 2012;119(10):2125-2132.

22. Campochiaro PA, Brown DM, Pearson A, et al; FAME Study Group. Long-term benefit of sustained-delivery fluocinolone acetonide vitreous inserts for diabetic macular edema. Ophthalmology. 2011;118(4): 626-635.

23. ILUVIEN ${ }^{\circledR}$. Summary of Product Characteristics. Available from: https://www.medicines.org.uk/emc/medicine/27636. Accessed May 30, 2016.

Clinical Ophthalmology

\section{Publish your work in this journal}

Clinical Ophthalmology is an international, peer-reviewed journal covering all subspecialties within ophthalmology. Key topics include: Optometry; Visual science; Pharmacology and drug therapy in eye diseases; Basic Sciences; Primary and Secondary eye care; Patient Safety and Quality of Care Improvements. This journal is indexed on Submit your manuscript here: http://www.dovepress.com/clinical-ophthalmology-journal
24. Bressler SB, Qin H, Beck RW, et al; Diabetic Retinopathy Clinical Research Network. Factors associated with changes in visual acuity and central subfield thickness at 1 year after treatment for diabetic macular edema with ranibizumab. Arch Ophthalmol. 2012;130(9):1153-1161.

25. Browning DJ, Glassman AR, Aiello LP, et al; Diabetic Retinopathy Clinical Research Network. Relationship between optical coherence tomography-measured central retinal thickness and visual acuity in diabetic macular edema. Ophthalmology. 2007;114(3):525-536.

26. Alasil T, Keane PA, Updike JF, et al. Relationship between optical coherence tomography retinal parameters and visual acuity in diabetic macular edema. Ophthalmology. 2010;117(12):2379-2386.

27. Uji A, Murakami T, Nishijima K, et al. Association between hyperreflective foci in the outer retina, status of photoreceptor layer, and visual acuity in diabetic macular edema. Am J Ophthalmol. 2012;153(4): 710-717.

28. Sakamoto A, Nishijima K, Kita M, Oh H, Tsujikawa A, Yoshimura N. Association between foveal photoreceptor status and visual acuity after resolution of diabetic macular edema by pars plana vitrectomy. Graefes Arch Clin Exp Ophthalmol. 2009;247(10):1325-1330.

29. Bonnin S, Tadayoni R, Erginay A, Massin P, Dupas B. Correlation between ganglion cell layer thinning and poor visual function after resolution of diabetic macular edema. Invest Ophthalmol Vis Sci. 2015; 56(2):978-982.

30. Carpineto P, Ciancaglini M, Di Antonio L, Gavalas C, Mastropasqua L. Fundus microperimetry patterns of fixation in type 2 diabetic patients with diffuse macular edema. Retina. 2007;27(1):21-29.

31. Vujosevic S, Pilotto E, Bottega E, Benetti E, Cavarzeran F, Midena E. Retinal fixation impairment in diabetic macular edema. Retina. 2008; 28(10):1443-1450.

32. Dubois-Roussel C, Dupas B, Erginay A, Massin P, Tadayoni R. Increased fixation stability after intravitreal treatment for chronic diabetic macular edema: a marker of favorable visual outcome. Poster 1777 - A0210 presented at: 2015 Annual meeting of the Association for Research in Vision and Ophtalmology (ARVO); May 3-7, 2015; Denver, Colorado.

33. Schmit-Eilenberger VK. A novel intravitreal fluocinolone acetonide implant (Iluvien ${ }^{\mathbb{R}}$ ) in the treatment of patients with chronic diabetic macular edema that is insufficiently responsive to other medical treatment options: a case series. Clin Ophthalmol. 2015;9:801-811.

34. Downey L, Chakravarthy U. Exploratory analyses of long-term visual outcomes based on baseline vision in patients with chronic and nonchronic diabetic macular oedema (DMO) treated with fluocinolone acetonide (FAc). Poster 221 presented at: Annual Congress 2015 of the The Royal College of Ophthalmologists; May 19-21, 2015, Liverpool, UK.
PubMed Central and CAS, and is the official journal of The Society of Clinical Ophthalmology (SCO). The manuscript management system is completely online and includes a very quick and fair peer-review system, which is all easy to use. Visit http://www.dovepress.com/ testimonials.php to read real quotes from published authors. 